Motrivivência Ano XXIV, No 38, P. 247-261 Jun./2012

http://dx.doi.org/10.5007/2175-8042.2012v24n38p247

\title{
METODOLOGIA DO ENSINO E DA PESQUISA EM SOCIOLOGIA DO ESPORTE NA UNIVERSIDADE FEDERAL DO PARANÁ: o programa investigativo do Centro de Pesquisa em Esporte, Lazer e Sociedade
}

\author{
Juliano de Souza? \\ Cristina Carta Cardoso de Medeiros ${ }^{2}$ \\ Bárbara Schausteck de Almeida ${ }^{3}$ \\ Wanderley Marchi Júnior ${ }^{4}$
}

\section{RESUMO}

No presente artigo procuramos apresentar algumas nuanças do desenvolvimento da Metodologia do Ensino e da Pesquisa em Sociologia do Esporte na Universidade Federal do Paraná (UFPR), recorrendo, para tanto, a algumas das experiências e iniciativas compartilhadas entre professores e alunos envolvidos em atividades na Graduação e Pós-Graduação em Educação Física desse mesmo estabelecimento de ensino. $\mathrm{Na}$ primeira parte do texto, nos propomos a registrar então a experiência vivenciada por um dos grupos de pesquisa dessa instituição no que tange à dinâmica de trabalho e aos procedimentos teórico-metodológicos adotados para o tratamento sociológico do fenômeno esportivo moderno. Na segunda parte do texto, por sua vez, expomos o formato da disciplina de "Sociologia do Esporte" no Curso de Bacharelado em Educação Física da UFPR.

Palavras-chave: Sociologia do Esporte; Metodologia da Pesquisa; Metodologia do Ensino Superior.

1 Mestre e doutorando em Educação Física pela Universidade Federal do Paraná.

Contato: julianoedf@yahoo.com.br

2 Doutora em Educação pela UFPR. Docente dos Programas de Pós-Graduação em Educação e Educação Física da Universidade Federal do Paraná. Contato: cricaccm@gmail.com

3 Mestre e doutoranda em Educação Física pela Universidade Federal do Paraná. Contato: barbara.edf@ufpr.br

4 Doutor em Educação Física pela Unicamp. Coordenador do Centro de Pesquisas em Esporte, Lazer e Sociedade (CEPELS). Vice-presidente da Asociación Latinoamericana de Estudios Socioculturales del Deporte (ALES$D E$ ). Docente dos Programas de Pós-Graduação em Educação Física e Sociologia da Universidade Federal do Paraná. Professor visitante na West Virginia University. Contato: marchijr@ufpr.br 


\section{INTRODUÇÃO}

No presente texto propomos ensaiar uma reflexão de caráter epistemológico que, dentre outras possibilidades analíticas, nos permita compreender algumas das formas com que tem sido desenvolvida e conduzida a Metodologia do Ensino e da Pesquisa em "Sociologia do Esporte" na Universidade Federal do Paraná (UFPR). Para tanto, recorremos, a algumas das experiências e iniciativas que vêm sendo compartilhadas entre alunos e professores diretamente envolvidos na Graduação e na Pós-Graduação em Educação Física da UFPR e que, além disso, integram o corpus de pesquisadores empenhados em atividades de produção e de divulgação científica no Centro de Pesquisa em Esporte Lazer e Sociedade (CEPELS) dessa mesma instituição.

É importante notarmos que a experiência com a disciplina de "Sociologia do Esporte" na Graduação em Educação Física da UFPR iniciou-se sistematicamente no ano de 2005. No entanto, discussões de cunho sociológico acerca da realidade social da Educação Física já vinham se fazendo presentes desde o ano de 1998 na figura da então disciplina de "Diagnose da realidade contemporânea" que, no ano de 2002, acabou sendo substituída pela disciplina "Aspectos sociológicos da Educação Física". Objetivamente falando, foi, portanto, apenas no ano de 2005 que, por conta da revisão curricular do curso de Educação Física da UFPR em 2004, as turmas de Licenciatura passaram a contar com a disciplina de "Sociologia e Educação Física" e o curso de Bacharelado, por conseguinte, com a então disciplina formalizada de "Sociologia do Esporte", condição que permanece até a atualidade.
Outro marco importante a ser pontuado nesse contexto que estamos recuperando se deu no ano de 2002, porém no âmbito da Pós-Graduação em Educação Física (PPGEF) da UFPR ou, melhor dizendo, no então recém-criado Programa de Mestrado. Trata-se, mais precisamente, da sistematização e oferta da disciplina de "Esporte e Sociedade" que até o ano de 2005 se constituía como disciplina obrigatória do programa, independentemente das linhas de pesquisa nas quais os alunos estivessem alocados. Entretanto, no ano de 2006, a referida disciplina passou a ser optativa, muito embora contivesse e contenha um caráter obrigatório para os alunos da linha de "Sociologia e História do Esporte e Lazer".

Concomitantemente a essas iniciativas docentes apresentadas, devemos pontuar como fator decisivo para constituição de uma unidade teórico-metodológica em torno do tratamento do esporte e do lazer no âmbito da Graduação e Pós-Graduação em Educação Física da UFPR, a criação interna do Centro de Pesquisa em Esporte, Lazer e Sociedade em 1998, bem como sua formalização e cadastramento em 2002 no Conselho Nacional de Desenvolvimento Científico e Tecnológico (CNPq). Dizemos isso porque existe uma nítida correspondência entre o "fazer sociológico" apresentado na disciplina de "Sociologia do Esporte" com os pressupostos teórico-metodológicos que têm orientado as pesquisas produzidas nessa instituição e disseminadas no campo acadêmico-científico da Educação Física em nível de Brasil e América Latina.

Nesse caso, é importante frisar que temos trabalhado a "Sociologia do Esporte" na UFPR a partir da perspectiva de indissociabilidade entre a esfera do ensino e da pesquisa, algo que, no nosso ponto de 
vista, trata-se de uma iniciativa viável, até porque, segundo atesta a pesquisadora Ana Maria Dias (2009), as relações entre ensino, pesquisa e extensão, têm estado em pauta nas agendas de discussão dos atuais Fóruns de Pró-Reitores como uma tentativa de promover a integração entre as três instâncias do ensino superior que deveriam nortear a formação integral do estudante. Para esta autora, a relação entre ensino, pesquisa e extensão, quando bem articulada, conduz a mudanças significativas nos processos de ensino e de aprendizagem, fundamentando didática e pedagogicamente a formação profissional, operacionalizando a inter-relação entre as dimensões teóricas e práticas e democratizando o saber acadêmico, isto é, tornando-o acessível.

Um modelo de aprendizagem ancorado nesse conjunto de enunciados apontados por Dias (2009) e acrescido, obviamente, de diversificadas práticas pedagógicas, de uma nova organização curricular e da busca pela inter e transdisciplinaridade, é um dos caminhos potenciais aptos a nos direcionar, portanto, para a uma formação discente que não se restrinja apenas aos aspectos técnicos e formais das disciplinas, mas que contemple, em tão presente medida, aspectos sociais e políticos, promovendo, dentre outras coisas, uma conscientização crítica para o questionamento do que está estabelecido e dos novos rumos da sociedade.

Assim sendo, é na tentativa de edificar práticas de ensino, pesquisa e extensão que possam abranger o acima exposto, que um grupo de professores e alunos da Graduação e da Pós-Graduação da UFPR projeta e tem projetado, ao longo de mais de dez anos, suas ações na área da "Sociologia do Esporte", se esforçando continuamente para, por um lado, formar indivíduos que possam usufruir do conhecimento sociológico como uma forma de defesa social e, por outro, contribuir com a consolidação dessa área de pesquisa como um campo de investigação/atuação inter e transdisciplinar.

Nas linhas que seguem procuramos dar continuidade a essa discussão até aqui ensaiada. Objetivamos, nesse sentido, apresentar algumas nuanças e aspectos do desenvolvimento atual da Metodologia do Ensino e da Pesquisa em "Sociologia do Esporte" na UFPR não esquecendo, entretanto, das derivações extensionistas que advêm das outras duas outras ações acadêmicas, uma vez que estamos atentos à indissociabilidade entre ensino, pesquisa e extensão, consagrada com o princípio da autonomia universitária.

O texto está dividido em duas partes. Na primeira delas, registramos a experiência então vivenciada pelo CEPELS, mais especificamente pelo grupo de orientandos do Prof. Wanderley Marchi Júnior, no que diz respeito à dinâmica de trabalho e àqueles procedimentos teórico-metodológicos partilhados no intuito de se avançar no tratamento e dimensionamento sociológico do fenômeno esportivo moderno. Na segunda parte, por sua vez, expomos o formato, isto é, os princípios sob os quais está organizada e é conduzida a disciplina de "Sociologia do Esporte" do Curso de Bacharelado em Educação Física da UFPR.

\section{A PESQUISA EM SOCIOLOGIA DO ES- PORTE NA UFPR - DINÂMICA DE TRA- BALHO E PROCEDIMENTOS TEÓRICO- -METODOLÓGICOS}

Antes mesmo de indicarmos aqueles referenciais bibliográficos e procedimentos 
de natureza teórico-metodológica que têm nos auxiliado no tratamento sociológico do esporte e do lazer na UFPR, é importante, num primeiro momento, nos atermos à própria dinâmica de organização do trabalho intelectual que orienta nossas atividades, até porque entendemos que a contribuição que, de certa forma, lançamos aos estudos em "Sociologia e História do Esporte e Lazer" no Brasil perpassa muito pela compreensão dessa dinâmica de trabalho aqui desenvolvida.

De antemão, convém frisamos que todos os orientadores da linha de "Sociologia e História do Esporte e Lazer" do PPGEF da UFPR possuem uma espécie de subgrupos de pesquisa integrados ao grupo de pesquisa maior que, nesse caso, é o CEPELS. Cada professor conduz sua dinâmica e proposta de trabalho no interior de seu subgrupo segundo aquilo que acredita e respeitando suas particularidades. Deste modo, as observações e comentários que a partir de agora faremos não devem ser generalizados, pois os mesmos dizem respeito e se circunscrevem ao espectro de relações vivenciadas no então subgrupo ou grupo de orientados conduzidos pelo Prof. Wanderley Marchi Júnior.

O grupo de orientação em evidência conta com alunos da Graduação, do Mestrado e do Doutorado em Educação Física da UFPR assim como com alunos do Doutorado em Sociologia dessa mesma instituição. Ambos os alunos estão em aperfeiçoamento e em busca de sua formação profissional/ titulação. No entanto, o objetivo de cada um dos agentes não se resume ao elencado e, nesse particular, visualizamos que o que está em pauta, muito mais que o estabelecimento de carreiras individuais, é o caminhar conjunto em prol do desenvolvimento de um campo consolidado da "Sociologia do Esporte" no Brasil e, por extensão, na América Latina.

Prova disso pode ser observado, dentre outras inserções, no próprio envolvimento que esses alunos têm tido na agenda de atividades da Asociación Latinoamericana de Estudios Socioculturales del Deporte (ALESDE) formalizada em 2008. Outro exemplo, também nesse sentido, seriam as atribuições que os estudantes de Mestrado e Doutorado desempenham na Revista da respectiva associação (Revista da ALESDE), que teve seu segundo número apresentado à comunidade acadêmica em abril de 2012.

No entanto, o que talvez de mais expressivo e do ponto de vista da materialização de conhecimento, esse grupo de pesquisadores esteja fazendo conjuntamente no sentido de lançar suas contribuições ao desenvolvimento da "Sociologia do Esporte" em nosso país, é a canalização de trabalhos em periódicos que são sintomáticos do próprio processo de constituição do esporte como objeto sociológico no Brasil. Essa inserção pode ser verificada na Revista Movimento, da Universidade Federal do Rio Grande do Sul, na Revista Brasileira de Educação Física e Esporte, da Universidade de São Paulo, na Revista Brasileira de Ciências do Esporte, dentre outras.

Avançando em nossa argumentação, importa frisar que para dar conta desse intenso programa de trabalho, esse grupo de estudantes se reúne semanalmente para planejar e atuar conforme as demandas relacionadas à ALESDE, à Revista da ALESDE e, principalmente, à proposta de divulgação das pesquisas nos congressos e nos periódicos nacionais e internacionais. Devemos ainda lembrar que tais reuniões, mediante cronograma estabelecido semestralmente, 
se prestam a um dos momentos que julgamos mais produtivos e importantes de nosso itinerário: a discussão das monografias, dissertações e teses em andamento no grupo.

Esse tipo de exercício/experiência, no nosso modo de compreender o metier acadêmico-científico daquele que apeteça ser um pesquisador/cientista, caracteriza-se como oportunidade ímpar para a formação de leitores e de escritores em "Sociologia do Esporte" atentos a uma gama de temáticas que se circunscrevem para além dos objetos de pesquisa que priorizam em suas monografias, dissertações e teses. No caso de nosso grupo, esse tipo de prognóstico é bastante presente, uma vez que inúmeras são as temáticas que estão pautando a produção das pesquisas de modo que a socialização do conhecimento possibilitado em função das leituras coletivas dos trabalhos contribui para uma formação polissêmica e o mais ampla possível dos pesquisadores.

Tal conjuntura inicialmente esquematizada nos remete por ora a necessidade de mencionarmos, ainda que rapidamente, as temáticas de pesquisa que foram/estão sendo priorizadas no grupo e que, em parte, se encontram dissolvidas em formas de capítulos na coletânea "Ensaios em Sociologia do Esporte" publicada em setembro de 2011 (MARCHI JÚNIOR, 2011). Todavia, não iremos nos restringir em esmiuçar a estrutura de cada um desses capítulos e apresentaremos as temáticas que tem guiado as propostas de investigação de nosso grupo em dois momentos bastante específicos: as pesquisas já desenvolvidas e as pesquisa em andamento.

De um lado e já adentrando no primeiro momento, teríamos as seguintes agendas: estudos sobre os processos de profissionalização, mercantilização e espetacularização do voleibol feminino no Brasil
(VLASTUIN, 2008; MOREIRA, 2009), do voleibol de praia (AFONSO, 2004; 2011), do taekwondo (PIMENTA, 2007) e do xadrez (SOUZA, 2010). Soma-se de forma muito próxima a esse panorama os estudos sobre a mídia esportiva impressa e televisionada (DOMINGUES, 2006; SILVA, 2007) e as disposições para a ação no espaço do futebol feminino (SALVINI, 2012).

Ainda integrando esse primeiro momento, temos os estudos sobre grupos sociais e sua relação com o fenômeno esportivo, expressos, particularmente, em uma pesquisa que aborda a violência no futebol e sua relação com os árbitros (BOSCHILIA, 2009), em outra pesquisa onde são retomadas as práticas e representações sociais de lazer nos clubes sociorrecreativos (RUIZ DA SILVA, 2007), em um trabalho sobre a dança (SILVA, 2011) e, por fim, em um estudo sobre os veteranos praticantes de basquete (PASTRE, 2006).

Completa esse quadro de estudos desenvolvidos, a realização de uma pesquisa sobre o financiamento esportivo do Comitê Olímpico Brasileiro (ALMEIDA, 2010), de uma segunda sobre as escolhas governamentais e políticas no campo esportivo paranaense (MARTINS, 2004), uma terceira sobre as políticas públicas de esporte e lazer no Brasil (STAREPRAVO, 2011) e de uma última sobre o estado da arte da "Sociologia do Esporte" em nosso país a partir da análise de dois periódicos científicos (FERREIRA, 2009).

Quanto às pesquisas em andamento no grupo, temos uma dissertação e cinco teses a serem defendidas nos próximos anos. Na dissertação em desenvolvimento vem sendo discutido, de um ponto de vista histórico-sociológico, o processo de disseminação do Kung Fu no território brasileiro. 
Em termos das pesquisas de doutoramento, algumas mais adiantadas e outras em fases mais iniciais, temos as seguintes temáticas de investigação dos alunos vinculados ao Programa de Pós-graduação em Sociologia, que serão defendidas a partir do segundo semestre de 2012: uma primeira pesquisa que aborda as relações do esporte amador nas instituições SESI e CSIT; a reconstituição da história-social do voleibol feminino brasileiro; e uma terceira pesquisa sobre a constituição do campo da "Sociologia do Esporte" no Brasil. Completa-se essa lista com dois trabalhos em andamento no PPGEF, sendo um deles sobre a candidatura e escolha do Rio de Janeiro como cidade-sede dos Jogos Olímpicos e Paraolímpicos de 2016 e o outro sobre o futebol brasileiro e a apreensão sociológica deste fenômeno no Brasil.

Em que pese essa breve descrição das temáticas que se fizeram e se fazem presentes na dinâmica de trabalho e agenda de pesquisa do grupo de pesquisadores em apreço, é importante, contudo, nesse momento nos concentrarmos em pontuar aqueles pressupostos teórico-metodológicos que, em certa medida, conferem uma identidade ao percurso científico do grupo, expresso, sobretudo, na produção das dissertações e teses supracitadas.

Antes disso, entretanto, há a necessidade de reconhecermos que alguns autores da chamada teoria sociológica contemporânea, de fato, têm sido mais centrais que outros no intuito de estudarmos o fenômeno esportivo, a saber, Pierre Bourdieu e Norbert Elias. Ao mesmo tempo, tem havido espaço para introdução de referenciais teóricos de outros autores, o que ocorre, a título de exemplo, com Max Weber, Émile Durkheim, Karl Mannheim, Charles Wright
Mills, Manuel Castells, Erving Goffman e, mais recentemente, com o trabalho daqueles autores que integram o chamado pensamento social brasileiro.

Não obstante esse panorama, Bourdieu e Elias, de fato, têm sido centrais e inspiradores em nosso percurso, especialmente, por defenderem em suas pesquisas, cada um ao seu modo, a reorientação de uma série de pressupostos teórico-metodológicos para guiar a pesquisa sociológica sem, no entanto, se pautarem em um cientificismo estéril e, em última instância, insensível às condições de dor, sofrimento e violência física e simbólica que grupos sociais inteiros são encerrados na sociedade. Dentre as enunciações teórico-metodológicas retrabalhadas por esses autores em suas respectivas obras, importa-nos pontuarmos a recondução da relação pesquisador/objeto e a correlação entre teoria e empiria.

No que se refere ao primeiro aspecto, isto é, a dialética pesquisador/ objeto, é importante frisarmos que temos sido influenciados pelo pressuposto eliasiano que reza sobre a necessidade de serem definidos objetos de estudo que o pesquisador realmente goste ou então seja bastante próximo. Ademais, Elias, ao longo de sua vida acadêmica, insistiu em chamar à atenção para o redirecionamento do conceito de sociedade e do próprio fazer sociológico, a partir do qual o pesquisador não deveria mais ser encarado como um agente exterior ao seu objeto de pesquisa, mas, antes de tudo, como um ser humano interdependente a outros. Dito de outro modo, Elias $(1980 ; 1998)$ via uma urgência em se romper com o modelo de investigação sociológica influenciado pela epistemologia das Ciências Naturais, em que a relação pesquisador/objeto deveria 
ser tão distante quanto possível, evitando assim, qualquer tipo de "contaminação".

Nesse mesmo quesito, entendemos ainda, em conformidade com Bourdieu, como positiva a escolha por um objeto de estudo com a qual o pesquisador tenha tido uma experiência prévia, desde que o mesmo procure objetivar sua relação com o objeto num empreendimento próximo àquilo que chamou de "objetivar o sujeito objetivante". Nesse particular, a metáfora do jogo de tênis - a do bom jogador que sempre procura antecipar as jogadas e "tendências" - utilizada por Bourdieu (2007) para explicar as vantagens sociais de se nascer no interior de determinado campo social, pode ser emprestada para pensar a relação pesquisador/ objeto em "Sociologia do Esporte".

É importante salientar que esse envolvimento mantido com determinada prática deve ser duplamente ponderado na construção de uma pesquisa sociológica que toma como objeto de investigação o próprio universo que açambarca essa prática. Nesse sentido, e se por um lado, uma indevida condução dessas experiências pode restringir ou induzir a análise, por outro, essas mesmas vivências, desde que devidamente evocadas e utilizadas, podem enriquecer o processo de descrição empírica bem como ampliar as perspectivas de leitura e compreensão dos fatos, já que determinados códigos do mundo social são bloqueados a determinados pesquisadores e, de forma contrária, revelados somente àqueles que foram formados no interior da prática em voga, com predisposição a incorporar as referências de comportamento correspondentes ao referido locus social.

Não obstante esse recenseamento, para que tais "vantagens" sejam concretizadas, de fato, como vantagens, é necessário realizar um rigoroso trabalho de transcrição metodológica que consiste em transformar o "conhecimento prático" advindo dos anos de envolvimento com uma prática social específica em "conhecimento aprofundado" garantido por conta do domínio de ferramentas teóricas e incursões sistemáticas sobre o objeto (BOURDIEU, 2008). Além disso, é oportuno notarmos que essa "proximidade" tornada "estranhamento" deve ser retomada e projetada rigorosamente na construção do objeto de pesquisa e do texto, o que, por conseguinte, requer cientificidade e objetividade nas Ciências Sociais tal como reivindicada na tradição sociológica durkheimiana posteriormente continuada, ou melhor, reinventada por Bourdieu.

Esse tipo de leitura nos remete, por indução, ao segundo aspecto mencionado, qual seja, à problematização das relações entre teoria/empiria. Para esse exercício, reportamo-nos brevemente às considerações tecidas pelo sociólogo brasileiro Renato Ortiz no texto "Ciências Sociais e trabalho intelectual" (2002). Ao integrar essa noção de objetividade tal como trabalhada na Sociologia francesa à de "imaginação sociológica" sistematizada no trabalho de Charles Wright Mills (1975), Ortiz apresenta uma concepção metodológica bastante original e afirma que é durante a escrita do texto que se realiza devidamente a construção do objeto. Para este autor (2002, p. 5-8), o objeto sociológico é um artefato feito pedaço por pedaço durante o exercer do ofício intelectual, quando o pesquisador, em lembrança ao artesão, deveria compor ou, melhor dizendo, "costurar" seu texto a partir de uma conjunção entre a "agulha" e os "fios", ou seja, entre a "problemática teórica" e os "dados". 
Essa arte de "costurar" reivindicada por Ortiz resulta naquilo que Mills (1975) chama de artesanato acadêmico. No caso da Sociologia e, por extensão, da própria "Sociologia do Esporte", o artesanato acadêmico toma alguns contornos bastante peculiares. Para escrita do seu texto, por exemplo, o sociólogo dispõe de vários pedaços de tecido - os dados empíricos - que, por sua vez, precisam ser ligados segundo os fios de novelos disponíveis, ou seja, as teorias. Entretanto, é necessária uma seleção criteriosa dos fios de modo que cada parte do tecido possa ser ligada satisfatoriamente à outra.

Essa adequação entre teoria e empiria é, incondicionalmente, um dos principais requisitos da "costura sociológica" ou, mais precisamente, do "fazer sociológico" tal como arrazoado pelo sociólogo Renato Ortiz e tal como expresso em nosso programa e agenda de pesquisas. Feitas essas observações, convêm passarmos neste momento ao segundo eixo que estrutura a presente exposição, de modo a problematizarmos, portanto, algumas nuanças do desenvolvimento da metodologia do ensino em "Sociologia do Esporte" na Graduação em Educação Física da UFPR.

O ENSINO DA SOCIOLOGIA DO ESPORTE NA UFPR - ABORDAGENS E ENCAMINHAMENTOS TEÓRICO-METODOLÓGICOS

Em consulta realizada com o auxílio de um questionário que objetivou avaliar as expectativas dos alunos e sua percepção sobre a disciplina de "Sociologia do Esporte" no sexto período do Curso de Bacharelado em Educação Física da UFPR,${ }^{5}$ percebeu-se, após tabulação dos dados, que 90\% dos alunos da turma tinham curiosidade sobre o conteúdo tratado pela "Sociologia do Esporte" e que essa curiosidade os levaria a aprofundar suas leituras e estudos na área. Nas respostas de outra questão, apurou-se que $63 \%$ da turma considerava, inclusive, que a "Sociologia do Esporte" poderia gerar interesse para a realização de uma monografia de conclusão de curso ou para o ingresso em grupos de estudo especializados. De forma mais contundente e expressiva, descobriu-se que $100 \%$ dos alunos achavam significativos/relevantes para a sua formação profissional os conteúdos abordados pela disciplina em questão, alegando que estes poderiam auxiliar em uma compreensão diferenciada do mundo em que vivem.

O que se descreve acima é significativo, ainda mais ao recuperar Melo (1997) quando analisa o ensino da História na formação dos educadores físicos. Mesmo alertando que não se poderia reduzir às constatações que afirmam que os que vêm cursar a Graduação em Educação Física, na maioria dos casos, têm maior identificação com disciplinas ligadas às Ciências Exatas e Biológicas, sob o risco de desconsiderar importantes modificações no perfil do estudante da área, são invariavelmente possíveis de serem percebidos questionamentos sobre as disciplinas ligadas às Ciências Humanas

5 Tal questionário fez parte de um exercício didático realizado em sala de aula, cujo objetivo foi desvelar o que os alunos compreendiam por "Sociologia do Esporte". A tarefa consistiu (1) na leitura de um texto de Introdução à "Sociologia do Esporte", pelos trinta alunos integrantes da turma, (2) na discussão em equipe sobre as informações contidas no texto, (3) no preenchimento de algumas questões relativas à interpretação do grupo sobre o texto e (4) em algumas reflexões complementares que foram incluídas as perguntas cujas respostas foram tabuladas para este artigo. 
para a prática diária do futuro profissional de Educação Física.

$\mathrm{O}$ autor diagnostica que, de fato, existe um entendimento de consenso com relação ao contexto de formação deste futuro profissional e o grande interesse por disciplinas em que a preocupação da aplicabilidade objetiva seja logo suprida. Esta concepção seria, sem dúvida alguma, responsável por legar às disciplinas ligadas às Ciências Humanas, tais como História e Sociologia, uma restrita função e responsabilidade para aqueles que, por ventura, acreditam que a formação e preparação profissional têm um formato determinado e o intuito de fornecer fórmulas fechadas, soluções lineares e modelos de atuação a serem seguidos irrefletidamente. Pensando sobre isso, Melo (1997, p. 57) pondera que

[...] a graduação deve preparar para a atuação profissional não através de fórmulas e modelos fechados. A graduação deve dar condições, por meio de uma preparação teórica aprofundada, para que o aluno possa recriar constantemente sua atuação, a partir da compreensão da realidade que o cerca, dos valores em jogo, das especificidades da atuação e das possibilidades de que pode dispor para alcance de seus objetivos. A graduação estaria preocupada em preparar o aluno para pensar/repensar sua atuação, entendendo que há a necessidade de uma compreensão teórica por trás de toda atuação, que nunca é só prática, mas indissociadamente teórico-prática.

Voltando à atividade didática aplicada na turma de Bacharelado em Educação Física da UFPR e recuperando a perspectiva de desvelamento do mundo atribuída pelos alunos à disciplina em questão, foi possível de observar nos questionários a veiculação de respostas que remetem a alguns temas circunscritos ao espectro de estudos empreendidos e contemplados no próprio CEPELS. Dentre as temáticas em "Sociologia do Esporte" que mais chamam a atenção dos discentes citam-se: esporte e globalização, esporte e violência, doping, a espetacularização do esporte, a influência da mídia sobre o esporte, as políticas públicas e o estudo sociológico de modalidades.

É importante reiterarmos que se tais temáticas mencionadas, por um lado, coincidem com as agendas de pesquisas dos professores/pesquisadores da UFPR, por outro, também vão ao encontro e fazem parte da própria proposta curricular adotada pelo grupo de professores que ministram a disciplina de "Sociologia do Esporte" nessa instituição, visto que a própria estrutura de ensino não é retomada por esses profissionais de forma estanque à dimensão de pesquisa e vice-versa, conforme atestado por nossas vivências.

No entanto, esse tipo de encaminhamento eleito não significa que trabalhamos a "Sociologia do Esporte" na Graduação como se fosse uma mera coextensão do que é desenvolvido em nível de Mestrado e Doutorado. Em outras palavras, valemo-nos sim dos mesmos pressupostos teórico-metodológicos sistematizados na Sociologia Reflexiva de Bourdieu e na Sociologia Configuracional de Elias (quanto ao envolvimento pesquisador/ objeto e quanto à relação entre empiria e teoria) conforme expusemos na seção anterior, mas, em contrapartida, retomando-os de uma forma mais acessível e compatível com o grau de desenvolvimento dos alunos de Graduação de forma a integrá-los numa efetiva e bem sucedida experiência de iniciação científica. 
Para esse tipo de iniciativa, a disciplina de "Sociologia do Esporte" na UFPR está organizada a partir de três eixos, dos quais fazem partem algumas unidades didáticas que abrangem os procedimentos de pesquisa, tal como anteriormente expusemos. Importa frisar que tais procedimentos, de natureza didático-metodológica, prescrevem o emprego de uma variação de modelos no ensino superior. Ao invés de uma abordagem tecnicista em que há uma predominância de uma pedagogia diretiva com ênfase em aspectos instrumentais da didática e da adoção de um modelo fixista de postura educacional meramente informativa, procura-se, a partir da dinamização e dialetização do processo de aprendizagem, conduzir a aula adotando um modelo pedagógico relacional em que o aluno construa o conhecimento sobre um material cognitivamente interessante e significativo, de uma maneira crítica e não conservadora. ${ }^{6}$ Sem crer tratar-se de um formato único mais apropriado e no intuito de possibilitar reflexões e intercâmbio de experiências em planejamento e metodologia de ensino em "Sociologia do Esporte", são descritos na sequência os três eixos que orientam o desenvolvimento da disciplina na Graduação.

O primeiro eixo, de caráter introdutório, diz respeito a uma iniciação ao pensamento sociológico a partir de uma contextualização sócio-histórica das origens da Sociologia, bem como sua definição e sua caracterização como elemento fundamental na compreensão, análise e interpretação do mundo social. A experiência dos últimos anos tem reforçado a importância desse primeiro eixo que, por seu caráter introdutório, rompe algumas barreiras e preconceitos quanto a um possível caráter abstrato e eminentemente teórico do conhecimento sociológico, advindos do senso comum. Ainda neste eixo, também são contempladas discussões que dizem respeito ao fazer sociológico e ao trabalho intelectual, momento em que os alunos passam a questionar suas práticas e levantar as problemáticas próprias ao âmbito da Educação Física e do esporte.

De forma mais pontual, aborda-se as relações entre a Educação Física e a "Sociologia do Esporte", além dos significados e objetivos que permeiam o estudo do esporte como fenômeno social, elencando-se, igualmente, questões e categorias sociológicas para a análise do fenômeno esportivo moderno. As aulas tornam-se mais motivantes quando essas primeiras "ferramentas" são indicadas, transcendendo a perspectiva do senso comum. Assim, interrogar os fatos sociais com as expressões "será", "por que" e "como" auxilia a progredir, respectivamente, da dúvida e reflexão, passando então pelas respostas do senso comum e, finalmente, levantando hipóteses e identificando processos. Para trabalhar com o "como", ou seja, com a construção das hipóteses e com a articulação dos possíveis processos que auxiliam na compreensão do fenômeno esportivo, é que nos reportamos a uma série de categorias sociológicas.

As categorias sociológicas trabalhadas na disciplina foram elencadas a partir de autores das Ciências Sociais, não necessariamente relacionados aos estudos do esporte, porém cujos constructos teóricos auxiliam na compreensão de fenômenos

6 Para outras reflexões sobre diferentes modelos pedagógicos, consultar: BECKER, F. Modelos pedagógicos e modelos epistemológicos. In: BECKE, F. Educação e construção do conhecimento. Por Alegre: Artmed, 2001. 
em evidência no campo esportivo. São as categorias e os principais autores referência: catarse (Norbert Elias e Eric Dunning), socialização (Émile Durkheim), distinção social (Pierre Bourdieu), secularização (Max Weber e Allen Guttmann), racionalização (Max Weber), dominação ideológica (Karl Marx), resistência (Karl Marx), identidade (Serge Moscovici, Zygmunt Bauman e Manuel Castells), diversidade (Manuel Castells e Zygmunt Bauman), inclusão social (Norbert Elias) e corporeidade (David Le Breton).

Neste momento de desenvolvimento da disciplina, não há uma expectativa arraigada na compreensão das categorias em suas complexidades teóricas ou um aprofundamento nos autores-referência, mas a principal intenção é mostrar aos alunos de que forma um conceito considerado inicialmente abstrato pode ser incorporado e auxiliar na compreensão do cotidiano. As análises auxiliadas com essas categorias sociológicas são reforçadas através de exercícios teórico-práticos de interpretação de notícias e reportagens levantadas pelos próprios alunos, conforme seus interesses.

Importante ressaltar que tal etapa vincula-se ao segundo eixo do curso, no qual se procura abordar perspectivas teóricas e as possibilidades de estudo em "Sociologia do Esporte". Com uma compreensão mais desenvolvida sobre o que é a "Sociologia do Esporte", de que forma seus estudos se materializam e principalmente com um olhar crítico e questionador sobre os fatos sociais, são apresentados alguns autores e suas teorias, tanto da Sociologia Clássica quanto da Sociologia Contemporânea e suas possibilidades de aplicação em estudos de cunho sociológico do esporte. A partir destes referenciais são tratados temas variados circunscritos ao universo esportivo, tais como: mídia, violência, globalização, política, economia, esporte como prática social e pedagógica, a construção social do corpo e os signos incorporados, além das instituições e organizações sociais do esporte.

O terceiro eixo, por sua vez, busca a partir de exercícios práticos, seja utilizando como recurso didático pesquisas de campo, seminários ou abordagem de fatos cotidianos, uma aplicação sistematizada das perspectivas teóricas e categorias de análise em objetos da área do esporte. Nesse momento, os alunos já possuem um espectro maior de ferramentas que os auxiliam na "lapidação da matéria-prima bruta e na consequente confecção do artesanato intelectual" (ORTIZ, 2002), ou em outras palavras, já têm à sua disponibilidade as categorias e teorias sociológicas a serem utilizadas como elementos de compreensão de fatos sociais para além da perspectiva do senso comum, resultando numa análise ou interpretação sociológica um pouco mais sofisticada.

Finalmente, devemos sublinhar que a disciplina com seus procedimentos e unidades didáticas, é coerente com as investigações realizadas no grupo de estudos, em que se postula também que a carreira dos futuros professores universitários não está pautada somente no domínio de conhecimento da especialidade em que cursam a Pós-Graduação, requerendo esforços somente na dimensão científica. Existe, nesse sentido, uma preocupação na preparação pedagógica desses estudantes, através da prática docente, para que compreendam que a concepção de docência no ensino superior e sua atuação profissional requerem saberes e competências diferenciadas que extrapolam a erudição das áreas específicas. 
Deste modo e para além dos aspectos técnicos e organizacionais da disciplina, o que envolve as estratégias de ensino, as formas de avaliação e as questões metodológicas, reforça-se aos envolvidos em prática docente na "Sociologia do Esporte" a importância de se levar em consideração os agentes do processo de ensino-aprendizagem, as formas como estes sistematizam o conhecimento, bem como ter metas e objetivos educacionais bem definidos, convergindo ações para a construção de um aluno crítico que possa problematizar o já construído e produzir novos conhecimentos para atuar e contribuir de forma responsável no universo social com todos os desafios que este apresenta.

\section{CONSIDERAÇÕES PARA O FECHAMENTO}

O presente texto teve como intuito prover à comunidade acadêmica um relato de experiência e de reflexão sobre o ensino e pesquisa em "Sociologia do Esporte", para, a partir de um exemplo metodológico pontual, lançar contribuições para possíveis discussões sobre um formato mais eficiente para esta disciplina nos cursos de Graduação em Educação Física e, muito particularmente, para afirmar a relevância da efetivação da mesma nas estruturas curriculares destes cursos de formação no país.

Tal afirmativa, por conseguinte, deriva do diagnóstico desta área de conhecimento no Brasil como uma disciplina emergente de investigação (SOUZA; MARCHI JÚNIOR, 2010), o que nos permite inferir que a "Sociologia do Esporte" como matéria de ensino também busca delineamento para um caminho de consolidação nos cursos de formação em Educação Física. Afirma-se, além disso, que a "Sociologia do Esporte" como componente curricular de ensino está sendo constituída de forma progressiva, já que a disciplina está presente em alguns cursos de Graduação em Educação Física, ainda que não seja unânime quando se compara a existência dos grupos de estudo sobre o tema vinculado entre as diversas instituições de ensino superior no Brasil (FERREIRA, 2009).

Problematiza-se, nesse particular, que mesmo que outras disciplinas possam estar abordando assuntos relevantes para as discussões empreendidas em torno da "Sociologia do Esporte", a disciplina específica não se faz presente em todos os cursos de Educação Física em território nacional. Paralelo, portanto, a esse prognóstico e por via da objetivação de nossas próprias experiências nesse artigo, reitera-se, num primeiro momento, a importância de alavancar discussões complementares sobre a efetivação desta área de conhecimento na formação dos graduandos de Educação Física, bem como se recobra a necessidade de envolvimento conjunto e mútuo de alunos em processo de formação na Pós-Graduação, futuros pesquisadores e professores de nível superior que, a partir de uma profícua prática pedagógica, possam replicar e intervir em suas instituições de ensino.

Um exemplo dessa proposta e a subsequente ponderação de algumas de suas lógicas e implicações foram retomados nesse artigo com base no registro da experiência vivenciada pelos pesquisadores que integram o CEPELS e, especialmente, o grupo de orientação do Prof. Wanderley Marchi Júnior. A propósito, a comunhão gerada no referido grupo e seu compromisso acadêmico-científico é, em última instância, o que propulsiona as ações de ensino em "Sociologia do Esporte" na UFPR 
e, ademais, orienta o trabalho que se delineia nas etapas posteriores. Neste caso, a partir da proposta do artesanato intelectual, dos demais princípios metodológicos que prospectam a construção do conhecimento científico e do formato de condução da dinâmica de trabalho, este grupo, a exemplo do que outros grupos também já o fazem, tem conseguido resultados importantes para tornar sólido o espaço da "Sociologia do Esporte" no Brasil e na América Latina, ao mesmo tempo em que investe na formação de indivíduos críticos e atuantes na área de Educação Física.

\section{REFERÊNCIAS}

AFONSO, G. F. Voleibol de Praia: uma análise sociológica da história da modalidade (1985-2003). Dissertação (Mestrado em Sociologia). Universidade Federal do Paraná, Curitiba, 2004.

AFONSO, G. F. A reinvenção do voleibol de praia: agentes e estruturas de uma modalidade espetacularizada (1983-2008). Tese (Doutorado em Sociologia). Universidade Federal do Paraná, Curitiba, 2011.

ALMEIDA, B. S. O financiamento do esporte olímpico e suas relações com a política no Brasil. Dissertação (Mestrado em Educação Física). Universidade Federal do Paraná, Curitiba, 2010.

BECKER, F. Modelos pedagógicos e modelos epistemológicos. In: BECKE, F. Educação e construção do conhecimento. Por Alegre: Artmed, 2001.

BOSCHILIA, B. Futebol e violência em campo: análise das interdependências entre árbitros, regras e instituições esportivas. Dissertação (Mestrado em
Educação Física). Universidade Federal do Paraná, Curitiba, 2008.

BOURDIEU, P. Razões práticas: sobre a teoria da ação. Campinas/SP: Papirus, 2007.

BOURDIEU, P. Homo Academicus. Buenos Aires: Siglo XXI Editores Argentina, 2008.

DIAS, A. M. I. Discutindo caminhos para a indissociabilidade entre ensino, pesquisa e extensão. Revista Brasileira de Docência, Ensino e Pesquisa em Educação Física. Cristalina, vol.1, n. 1, pp. 37-52, agosto, 2009.

DOMINGUES, A. Jornalismo esportivo: uma análise sociológica do caderno Atenas 2004 do jornal Folha de São Paulo. Dissertação (Mestrado em Educação Física). Universidade Federal do Paraná, Curitiba, 2006.

ELIAS, N. Introdução a Sociologia. Lisboa: Edições 70, 1980.

FERREIRA, A. L. P. O estado da arte da sociologia do esporte no Brasil: um mapeamento da produção bibliográfica de 1997 a 2007. Dissertação (Mestrado em Sociologia). Universidade Federal do Paraná, Curitiba, 2009.

MARCHI JÚNIOR. (org.). Ensaios em Sociologia do Esporte. São Paulo: Factesh, 2011.

MARTINS, D. J. Q. A formulação e implementação de políticas públicas no campo do esporte no estado do Paraná entre 1987 e 2004. Dissertação (Mestrado em Educação Física). Universidade Federal do Paraná, Curitiba, 2004.

MELO, V. A. Por que devemos estudar História da Educação Física/Esportes nos cursos de Graduação? Motriz, Rio Claro, vol. 3, n.1, p. 56-61, jun. 1997. 
MILLS, C. W. A imaginação sociológica. Rio de Janeiro: Zahar, 1975.

MOREIRA, T. S. O voleibol feminino no Brasil: do amadorismo à profissionalização. Dissertação (Mestrado em Educação Física). Universidade Federal do Paraná, Curitiba, 2009.

ORTIZ, R. Ciências Sociais e trabalho intelectual. São Paulo: Olho d'água, 2002.

PASTRE, T. G. F. L. O basquetebol veterano do Paraná. Dissertação (Mestrado em Educação Física). Universidade Federal do Paraná, Curitiba, 2006.

PIMENTA, T. F. F. A constituição de um subcampo do esporte: o caso do taekwondo. Dissertação (Mestrado em Sociologia). Universidade Federal do Paraná, Curitiba, 2007.

RUIZ DA SILVA, M. Lazer nos clubes sócio-recreativos de Curitiba/ PR: a constituição de práticas e representações sociais. Dissertação (Mestrado em Educação Física). Universidade Federal do Paraná, Curitiba, 2007.

SALVINI, L. Novo Mundo Futebol Clube e o "velho mundo" do futebol: considerações sociológicas sobre o habitus esportivo de jogadoras de futebol. Dissertação (Mestrado em Educação Física). Universidade Federal do Paraná, Curitiba, 2012.

SILVA, C. L. Produção televisiva esportiva: um estudo sobre as ações e disposições dos agentes midiáticos a partir do programa Globo Esporte (regional/PR). Dissertação (Mestrado em Educação Física). Universidade Federal do Paraná, Curitiba, 2007.

SILVA, S. S. Habitus e práticas da dança: uma análise sociológica dos fatores que influenciam a prática da dança na cidade de Toledo/PR. Dissertação (Mestrado em Educação Física). Universidade Federal do Paraná, Curitiba, 2011.

SOUZA, J. O xadrez em xeque - uma análise sociológica da "história esportiva" da modalidade. Dissertação (Mestrado em Educação Física). Universidade Federal do Paraná, Curitiba, 2010.

SOUZA, J.; MARCHI JÚNIOR, W. Por uma gênese do campo da Sociologia do Esporte: cenários e perspectivas. Revista Movimento, Porto Alegre, vol. 16, n. 2, p. 45-70, abr./jun. 2010.

Starepravo, F. A. Políticas públicas de esporte e lazer no Brasil: aproximações, intersecções, rupturas e distanciamentos entre os subcampos político/burocrático e científico/ acadêmico. Tese (Doutorado em Educação Física). Universidade Federal do Paraná, Curitiba, 2011.

VLASTUIN, J. O caso da equipe de Voleibol Feminino Rexona (1997-2003): um estudo das inter-relações com a mídia esportiva. Dissertação (Mestrado em Educação Física). Universidade Federal do Paraná, Curitiba, 2008. 
Ano XXIV, n 38 , junho/2012

METHODOLOGY OF TEACHING AND RESEARCH IN SOCIOLOGY OF SPORT IN THE FEDERAL UNIVERSITY OF PARANÁ - the experiences of the Centro de Pesquisa em Esporte, Lazer e Sociedade

\begin{abstract}
In this paper we present some of the nuances of the ongoing development of the Methodology of Teaching and Research in Sociology of Sport at the Universidade Federal do Paraná (UFPR). For this purpose, we showed some of the experiences and initiatives shared among undergraduate and post-graduate students and professors of Physical Education. In the first part of the text, we propose to register the experience lived by one of the groups in this institution regarding to its work dynamic and theoreticalmethodological procedures commune in the treatment of the sociological phenomenon of modern sports. In the second part of the text, in turn, lays out the format upon which is conducted subject "Sociology of Sport" in the Course of Bachelor in Physical Education at UFPR.
\end{abstract}

Keywords: Sociology of Sport; Research Methodology; Methodology for Higher Education.

Recebido em: março/2012

Aprovado em: julho/2012 